\title{
Evaluation of Bone Gain and Complication Rates after Guided Bone Regeneration with Titanium Foils: A Systematic Review
}

\author{
Elisabet Roca-Millan ${ }^{1}\left[\right.$, Enric Jané-Salas ${ }^{2}$, Albert Estrugo-Devesa ${ }^{2}$ [D and José López-López ${ }^{2, *}$ \\ 1 Faculty of Medicine and Health Sciences (School of Dentistry), University of Barcelona, \\ 08907 Barcelona, Spain; erocamil@gmail.com \\ 2 Oral Health and Masticatory System Group-IDIBELL, Faculty of Medicine and Health \\ Sciences (School of Dentistry), Odontological Hospital University of Barcelona, University of Barcelona, \\ 08907 Barcelona, Spain; enjasa19734@gmail.com (E.J.-S.); albertestrugodevesa@gmail.com (A.E.-D.) \\ * Correspondence: jl.lopez@ub.edu or 18575jll@gmail.com
}

Received: 29 October 2020; Accepted: 23 November 2020; Published: 25 November 2020

\begin{abstract}
Guided bone regeneration techniques are increasingly used to enable the subsequent placement of dental implants. This systematic review aims to analyze the success rate of these techniques in terms of bone gain and complications rate using titanium membranes as a barrier element. Electronic and hand searches were conducted in PubMed/Medline, Scielo, Scopus and Cochrane Library databases for case reports, case series, cohort studies and clinical trials in humans published up to and including 19 September 2020. Thirteen articles were included in the qualitative analysis. Bone gain both horizontally and vertically was comparable to that obtained with other types of membranes more commonly used. The postoperative complication rate was higher that of native collagen membranes and non-resorbable titanium-reinforced membranes, and similar that of crosslinked collagen membranes and titanium meshes. The survival rate of the implants was similar to that of implants placed in native bone. Due to the limited scientific literature published on this issue, more randomized clinical trials comparing occlusive titanium barriers and other types of membranes are necessary to reach more valid conclusions.
\end{abstract}

Keywords: titanium membrane; titanium foil; occlusive titanium barrier; bone augmentation; guided bone regeneration

\section{Introduction}

The four classical principles of guided bone regeneration (GBR) are primary closure, angiogenesis, space maintenance and blood clot stability [1] (Figure 1).

Based on these concepts, different techniques and a wide variety of biomaterials have been developed with the aim of achieving greater predictability, lower risk of complications, lower morbidity and shorter operative time in this type of treatment, which is becoming more and more common $[2,3]$. Research on new biomaterials for bone regeneration is advancing rapidly; even recently they have been manufactured by combining biopolymers and natural nanoparticles [4,5]. Ideally, the proposed method should provide a solution to the four precepts $[2,3]$. 


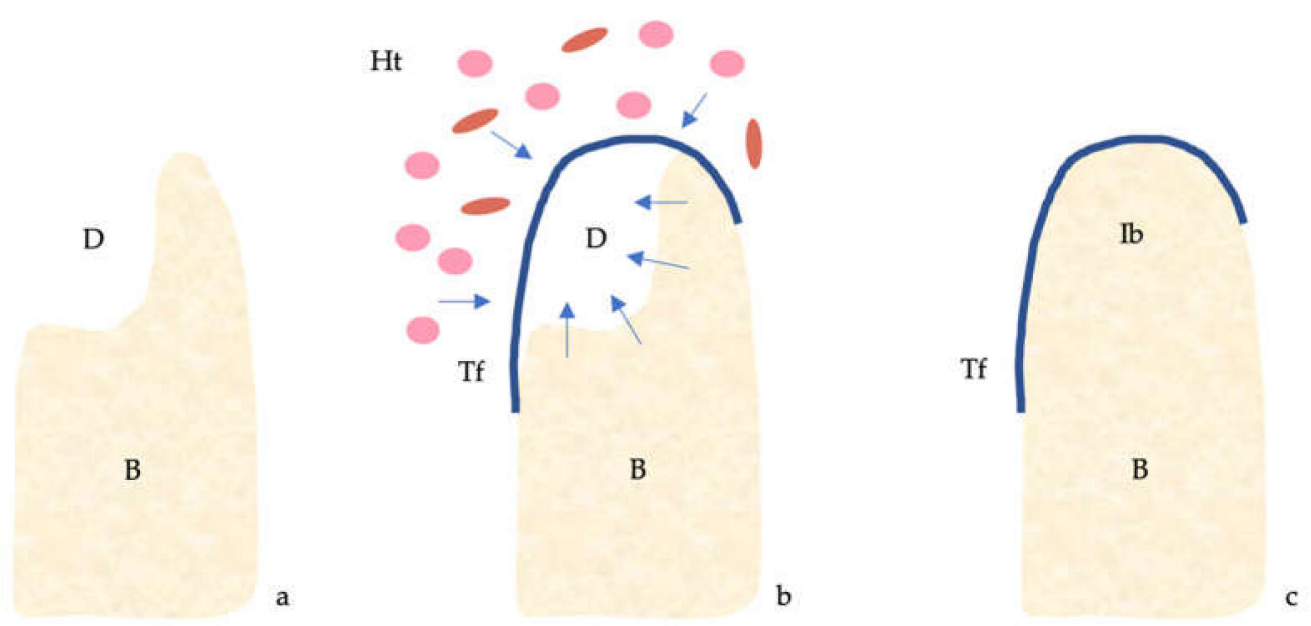

Figure 1. Guided bone regeneration (GBR) mechanism. (a) Bone defect. (b) The titanium barrier prevents the penetration of epithelial cells and fibroblasts and allows access to the defect of osteogenic and stem cells originating from the native bone. (c) Regeneration of the bone defect. Abbreviations: $\mathrm{B}$, bone; D, defect; $\mathrm{Ht}$, healing tissue; Ib, immature bone; Tf, titanium foil.

On the other hand, the properties that an ideal biomaterial should fulfill are osteogenesis, osteoconduction and osteoinduction. Therefore, autologous bone is considered the gold standard [2]. However, the great resorption, the unlimited availability, the morbidity and the longer surgical time represent inconveniences in its use. That is why a combination of several biomaterials is generally used in GBR procedures [2,3,6].

Since clot formation is the first and essential step in bone healing [7,8], in the last years, there have been numerous studies that focus on the use of blood concentrates (platelet-rich plasma (PRP), platelet-rich fibrin (PRF) and platelet-rich growth factor (PRGF)) in these surgical procedures [9-11].

However, due to the presence of erythrocytes, blood has a greater capacity to generate thrombin and activate platelets than these concentrates [12]. Likewise, the lower porosity and density of the fibrin layer present in the complete clot facilitate cell migration [13]. However, to benefit from its properties, it would be necessary to at least maintain the space and stabilize the clot [14-16].

To comply with these two principles, there are different types of membranes or barrier elements, such as titanium-reinforced polytetrafluoroethylene membranes, perforated titanium meshes and titanium foils [17]. The main drawback of the first two is the high exposure rate, associated with a high failure rate $[3,6,18]$. However, titanium barriers tolerate prolonged exposure to the oral environment, with good hygiene and the use of antiseptics to avoid bacterial colonization being essential [19-21].

Several studies published in recent years defend the use of these barrier elements in the regeneration of large maxillary atrophies [20-24], in post-extraction socket reconstruction $[19,25,26]$, in the regeneration of periodontal defects [27] and even simultaneously with implant placement [28].

The concept of using these barriers is to take advantage of the properties of the blood clot, which is why, in some studies, they are used without biomaterial filling [21,24]; although, in other publications, these membranes have been used in combination with PRF [19], allograft [20,22,23,29], xenograft $[25,26,30]$, mixed autograft and allograft [31] or even tricalcium $\beta$-phosphate [28].

Given that titanium barriers comply with the two aforementioned precepts and have tolerance to prolonged exposure, the objective of this systematic review is to study the success rate of GBR through the use of this type of membranes in terms of the amount of new bone formed and the complications associated with this surgical technique. 


\section{Materials and Methods}

This systematic review was conducted according to the guidelines of the Preferred Reporting Items of Systematic Reviews and Meta-Analyses (PRISMA) statement [32]. Before starting the review, a detailed protocol of the methodology was developed. The protocol was not registered.

\subsection{Focused Questions}

1. Is the use of occlusive titanium barriers alone or in combination with biomaterial a predictable treatment in terms of amount of new bone formed? (primary question)

2. What is the complication rate regarding membrane exposure and infection? (primary question)

3. What is the survival and success rate of implants placed after this regenerative procedure? (secondary question)

\subsection{PICO Question}

P: Patients with partial or total edentulism.

I: Guided bone regeneration using occlusive titanium barriers alone or in combination with biomaterials.

C: Guided bone regeneration using other type of membranes.

$\mathrm{O}$ : Amount of new bone formed and rate of membrane exposure and infection.

\subsection{Eligibility Criteria}

Inclusion criteria: Case reports, case series, cohort studies and clinical trials written in English or Spanish that analyze the use of titanium foils in GBR procedures were considered for inclusion.

Exclusion criteria: animal studies. No limitations were used for publication date, sample size, follow-up period, type of bone defect treated or filler biomaterial.

\subsection{Search Strategy}

An electronic search was performed by two reviewers (E.R-M and E.J-S) for articles published up to and including September 2020. The databases consulted were MEDLINE/PubMed, Scielo, Scopus and Cochrane Library. An additional hand search was conducted to identify potential articles of interest in the references of the studies found. Both searches were performed on 19 September 2020.

The following term combination was used in the electronic search: ("titanium membrane [All Fields]" OR "occlusive titanium barrier [All Fields]" OR "titanium foil [All Fields]") AND ("bone regeneration [All Fields]" OR "bone formation [All Fields]" OR "bone augmentation [All Fields]" OR "guided bone regeneration [All Fields]" OR "guided tissue regeneration [All Fields]").

\subsection{Study Selection}

After screening titles and discarding duplicates, those studies whose abstract met the inclusion criteria were selected. The full text of these articles was read to verify that they met the eligibility criteria. Disagreements during the study selection were solved by consulting a third author (J.L-L).

\subsection{Data Extraction and Method of Analysis}

The data were extracted by two authors (E.R-M and A.E-D) and entered into a data collection form (Microsoft Excel version 16.35). In case of disagreement, a third author (E.J-S or J.L-L) was consulted, to get a consensus. The following data were collected: author(s), year of publication, type of study, number of titanium foils, type of defect, filling material, time of membrane removal, amount of bone gain, percentage membrane exposure, percentage of infection, number of patients, number of implants placed, survival and success rates of the implants, and follow-up period. Corresponding authors were contacted and asked if they could provide missing data. To summarize the data, the mean rates of exposure, infection, implant survival and implant infection were calculated. 


\subsection{Quality Assessment and Risk of Bias}

The Strength of Recommendation Taxonomy (SORT) criteria were used to assess the quality of the evidence provided in the included studies [33]. This classification groups the articles into three levels: Level 1 (good-quality patient-oriented evidence), Level 2 (limited-quality patient-oriented evidence) and Level 3 (other evidence). Version 2 of the Cochrane Collaboration's tool for assessing risk of bias in randomized trials (RoB 2) [34] was implemented to evaluate the risk of bias of the randomized clinical trials and the Cochrane tool for assessing risk of bias in non-randomized studies of interventions (ROBINS-1) [35] was implemented to assess the risk of bias of the included retrospective cohort study.

\section{Results}

\subsection{Study Selection}

Through the electronic and manual searches, a total of 118 records were identified. After reading the titles and, if necessary, the abstracts and identifying duplicate articles, a total of 101 papers were discarded. Of these 17 studies assessed for eligibility, one was discarded after reading the full text because the titanium foil was placed in order to stabilize the jaw and prevent its fracture [36]. Three other articles were discarded, as they appear to be the same study as another two of the included papers but in earlier stages [20,21,23]. A total of 13 articles were included in the qualitative analysis [19,22,24-31,37-39] (Figure 2). A quantitative analysis could not be performed due to the lack of information provided and the great heterogeneity of the studies, in terms of sample size, type of defect to be regenerated, time of membrane removal and filling material used.

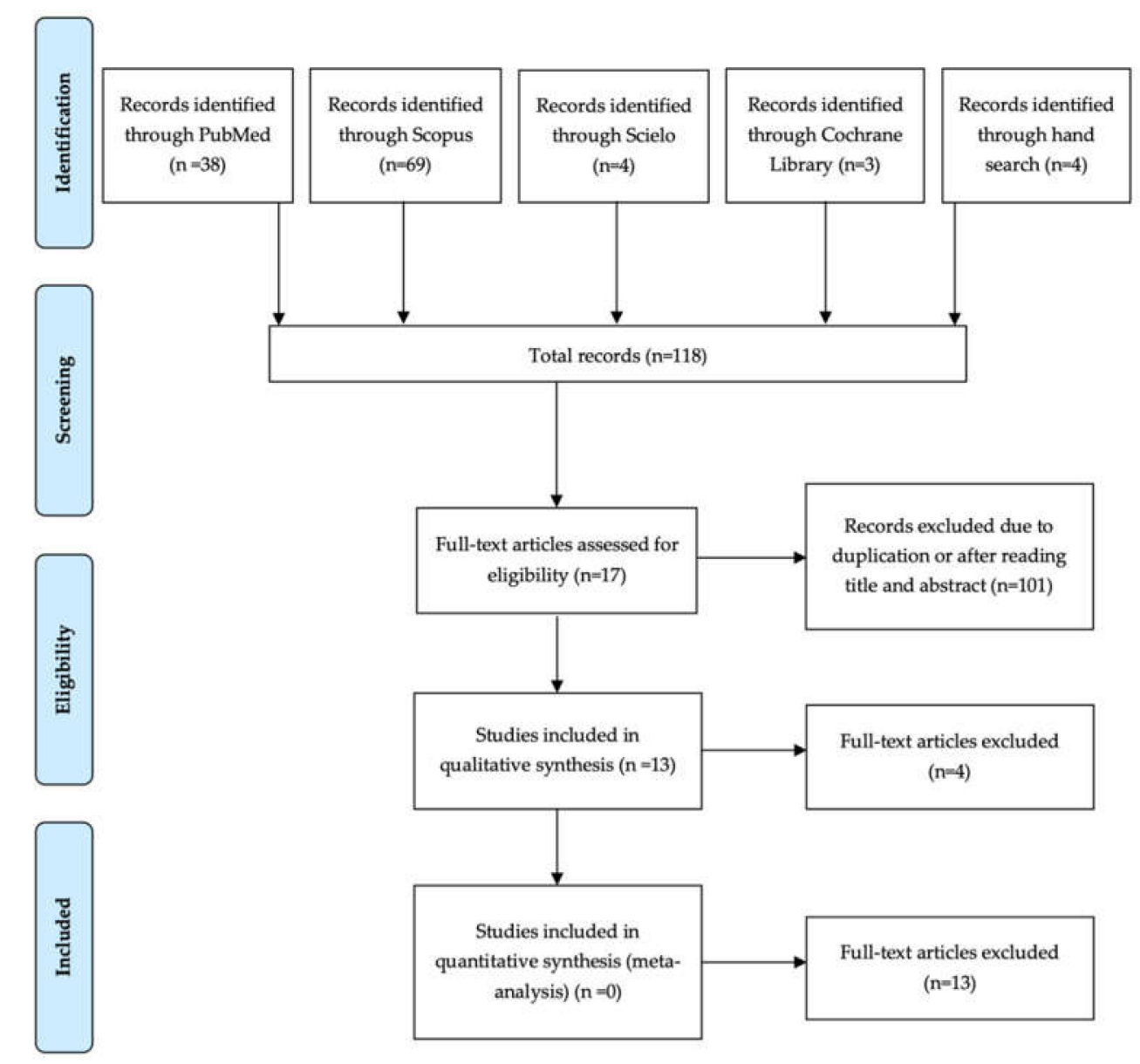

Figure 2. Preferred Reporting Items of Systematic Reviews and Meta-Analyses (PRISMA) flow diagram of selection process. 


\subsection{Study Methods and Characteristics}

Two of the included articles were case reports [28,30], seven were case series $[19,22,25,26,29,31,39]$, three were split-mouth randomized clinical trials $[27,37,38]$ and only one was a retrospective cohort study [24]. The studies were published between 1999 and 2020 (Figure 3 and Table 1).

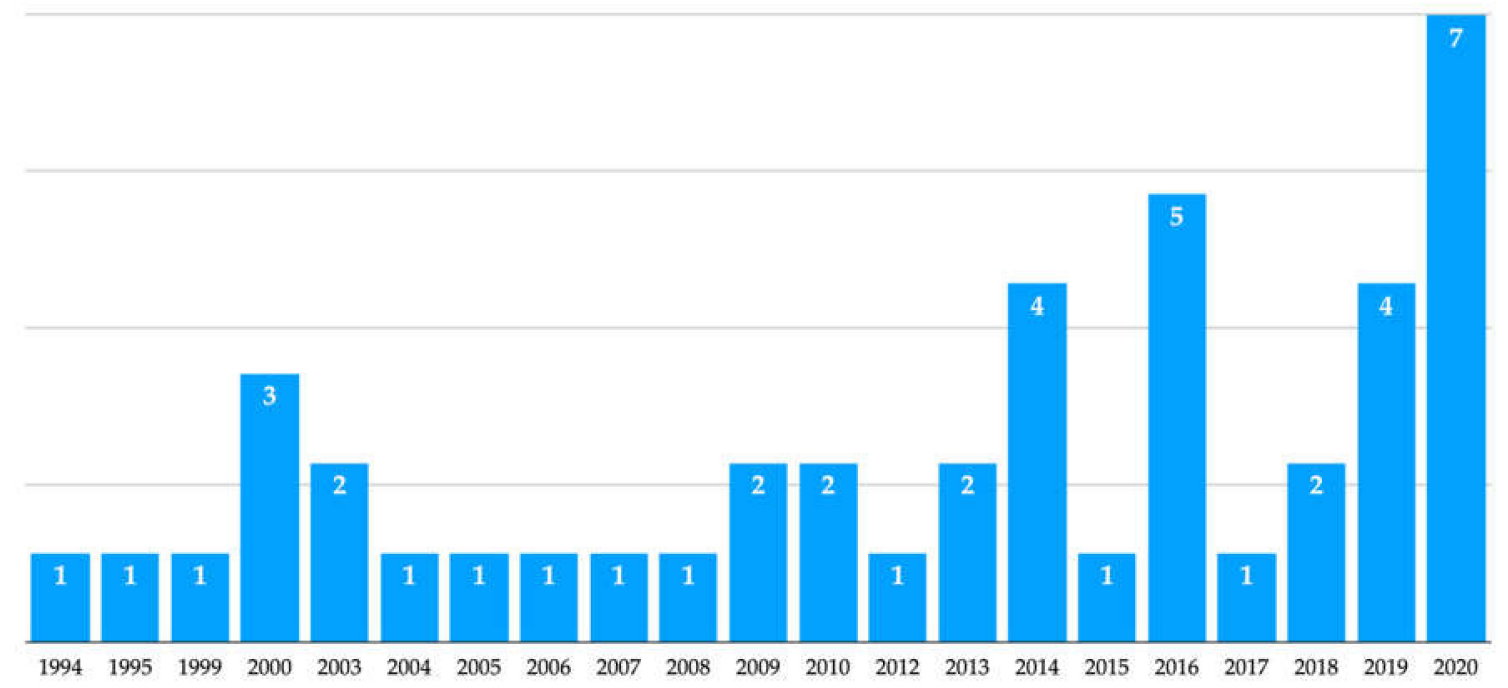

Figure 3. Results by year of the electronic search in PubMed.

The total population was 200 patients (72 women, 54 men, and 74 not specified), in which 260 titanium foils were placed. In two of the studies, the membrane was custom-fit manufactured from a previous computerized tomography [22,24]. The follow-up period was between two months and nine years. In six of the included studies $[19,22,24,26,28,30]$, implants were placed in the regenerated area, with 88 implants placed in 39 patients. The time of membrane removal was between 21 days and 17 months; although, in some studies, it is not specified [19,28,31].

A wide variety of bone defects were treated: horizontal [25,28-30,39], horizontal and vertical $[22,24,26,28,39]$, periodontal intrabony defects [27,37], post-extraction sockets [19,38], peri-implant defects [31,39] and sinus-floor augmentation [39].

The filling material was different depending on the study: blood clot [24,27,37,38], xenograft [25,26,30], allograft [22,29], $\beta$-Tricalcium phosphate [28], PRF or PRF + tricalcium phosphate + hydroxyapatite [19], autograft [38], autograft or/and hydroxyapatite [39] and autograft + xenograft [31].

\subsection{Quality Assessment and Risk of Bias}

According to the Strength of Recommendation Taxonomy (SORT) criteria, four of the studies included obtained a Level 2 of evidence $[24,27,37,38]$ while the others obtained a Level $3[19,22,25,26,28-31,39]$, so it should be noted that the quality of the included studies is limited and greater value should be given to the results obtained in Level 2 articles. Table 2 presents the risk of bias of the randomized clinical trials (RCT) $[27,37,38]$ and the cohort study [24] assessed by using RoB 2 and ROBINS-1, respectively, with an overall judgment of low-moderate risk of bias. The present review itself fulfils 22 items in the PRISMA statement [32]. 
Table 1. Summary of the included studies.

\begin{tabular}{|c|c|c|c|c|c|c|c|c|c|}
\hline Author & Type of Study & $\begin{array}{l}\text { Level of } \\
\text { Evidence }\end{array}$ & $\mathrm{N}$ (Titanium Foils) & Type of Defect & Filling Material & $\begin{array}{c}\text { Membrane } \\
\text { Removal (Months) }\end{array}$ & Bone Gain (mm) & Membrane Exposure (\%) & Infection (\%) \\
\hline Kfir et al., 2007 [19] & Case series & Level 3 & 15 & Post-extraction socket & PRF or PRF + TCP + HAP & NS & NS & $47 \%$ & $0 \%$ \\
\hline Bassi et al., 2016 [22] & Case series & Level 3 & 13 & $\mathrm{HV}$ & Allograft & $6.35 \pm 2.15$ & $5.9 \pm 2.1 \mathrm{~V} ; 8.9 \pm 3.5 \mathrm{H}$ & $38.5 \%$ & $0 \%$ \\
\hline Maeda et al., 2020 [25] & Case series & Level 3 & 15 & $\mathrm{H}$ & Xenograft & 21 days & $8.02 \pm 2.43(\mathrm{P1}) ; 8.71 \pm 2.26(\mathrm{P2}) ; 9.00 \pm 2.52(\mathrm{P} 3)$ & $100 \%$ (intentionally exposed) & $0 \%$ \\
\hline Perret et al., 2019 [26] & Case series & Level 3 & 6 & $\mathrm{HV}$ & Xenograft & 4 & $7.3 \pm 2.2(\mathrm{P} 1) 4.2 \pm 1.2(\mathrm{P} 2) \mathrm{V} ; 2.3 \pm 1.0 \mathrm{H}$ & $100 \%$ (intentionally exposed) & $0 \%$ \\
\hline Engelke et al., 2014 [28] & Case report & Level 3 & 2 & $1 \mathrm{HV} ; 1 \mathrm{H}$ & $\beta$-Tricalcium phosphate & $3 ; \mathrm{NS}$ & NS & $0 \%$ & $0 \%$ \\
\hline Molly et al., 2006 [24] & Retrospective study & Level 2 & 11 & $\mathrm{HV}$ & Blood clot & $9-17$ & NS & $45.5 \%$ & NS \\
\hline Toygar et al., 2009 [27] & RCT & Level 2 & 16 & Periodontal Intrabony Defect & Blood clot & $1-1.5$ & NS & $43.75 \%$ & NS \\
\hline Gaggl et al., 1999 [31] & Case series & Level 3 & 42 & $\begin{array}{c}\text { Peri-implant Defect } \\
\end{array}$ & Autograft + xenograft & NS & $4.5 \pm 0.2$ & $21.43 \%$ & $11.90 \%$ \\
\hline Beltrán et al., 2013 [30] & Case report & Level 3 & 1 & $\mathrm{H}$ & Xenograft & 7 & $4 \mathrm{~mm}$ & $0 \%$ & $0 \%$ \\
\hline Khanna et al., 2016 [37] & RCT & Level 2 & 12 & Periodontal Intrabony Defect & Blood clot & 5-6 weeks & $54.69 \%$ defect fill & $33.33 \%$ & $0 \%$ \\
\hline Pinho et al., 2006 [38] & RCT & Level 2 & 10 & Post-extraction socket & Blood clot (CS); autograft (TS) & Maximum 6 months & $8.80 \pm 2.93(\mathrm{C}) ; 8.40 \pm 3.35(\mathrm{~T})$ & $50 \%$ & $0 \%$ \\
\hline Watzinger et al., 2000 [39] & Case series & Level 3 & 112 & Different type defects & Autograft and/or hydroxyapatite & 4.6 & NS & $30 \%$ & NS \\
\hline
\end{tabular}

Abbreviations: $\mathrm{C}$, control; $\mathrm{CS}$, control socket; $\mathrm{H}$, horizontal; HAP, hydroxyapatite; $\mathrm{HV}$, horizontal and vertical; NS, not specified; $\mathrm{P}$, point; PRF, platelet-rich fibrin; RCT, randomized clinical trial; T, test; TCP, tricalcium phosphate; TS, test socket; V, vertical.

Table 2. Risk of bias across randomized clinical trials and the cohort study

\begin{tabular}{cccccc}
\hline Bias Domain ROBINS-1 & Molly et al. [24] & Bias Domain RoB 2 & Khanna et al. [37] & Pinho et al. [38] & Toygar et al. [27] \\
\hline Confounding & Low & Randomization process & Unclear & Unclear & \\
\hline Selection of participants & High & & & & \\
\hline Classification of interventions & Low & & & & \\
\hline Deviations from intended interventions & Low & $\begin{array}{c}\text { Deviations from intended } \\
\text { interventions }\end{array}$ & Low & Low & Low \\
\hline Missing data & Low & Missing data & Low & Unclear \\
\hline Measurement of outcomes & Low & Measurement of outcomes & Unclear & Low \\
\hline Selection of reported result & Unclear & Selection of reported result & Low & & \\
\hline Overall bias & Unclear & & & & \\
\hline
\end{tabular}




\subsection{Bone Gain}

Of the 13 studies included, four did not specify or evaluate the amount of new bone formed [19,24,27,28]. In two of them, a sufficient amount of bone was gained in all cases [19,28]. Another, which studied the regeneration of periodontal intrabony defects, did not evaluate this parameter [27]. The other one did not specify the values obtained but clarified that, in most cases, a sufficient bone augmentation was obtained for implant placement [24].

In the other nine studies, in which a wide variety of bone defects were treated, considerable bone gain was obtained after using titanium foils, regardless of the type of defect. Vertical bone gain, excluding the post-extraction sockets, was between $4.5 \mathrm{~mm}$ (autograft + xenograft) [31] and $7.3 \mathrm{~mm}$ (xenograft) [26]. Horizontal bone gain was between $2.3 \mathrm{~mm}$ (allograft) [29] and $9 \mathrm{~mm}$ (xenograft) [25]. In the study that quantified the regeneration of periodontal intrabony defects, a filling of $54.69 \%$ was obtained [37].

\subsection{Complications}

In two of the studies, titanium barriers were intentionally left exposed [25,26]. Three other articles reported not having had any exposure prior to membrane removal $[26,27,29]$. In the rest of the studies, the exposures ranged between $21.43 \%$ and $50 \%$ [19,22,24,27,31,37-39]. The mean percentage of accidental exposure was $23.81 \%$. Only one article reported having cases of graft infection, with a percentage of $11.9 \%$ [31].

It must be taken in account that one of these articles reported an exposure of the $43.75 \%$ of the membranes; however, this percentage is higher, since the study discarded those patients who had had an exposure greater than a quarter of the membrane in the first four to six weeks [27].

As another complication, in one of the studies two patients were excluded due to displacement of the titanium barrier [37].

\subsection{Implant Survival and Success Rates}

In six of the included studies $[19,22,24,26,28,30]$, implants were placed in the regenerated area, with 88 implants placed in 39 patients. The mean survival rate was $96.5 \%$ (82.6-100\%), and the mean success rate was $91.3 \%(82.6-100 \%)$. It must be considered that only two studies evaluated the success rate $[22,26]$. The follow-up period for these implants was between one and nine years (Table 3). The study with the lowest survival rate was the one with the longest follow-up period [24].

Table 3. Implants survival and success rates.

\begin{tabular}{cccccc}
\hline Author & N Patients & N Implants & Survival Rate & Success Rate & Follow-Up \\
\hline Kfir et al., 2007 [19] & 8 & 9 & - & - & - \\
\hline Bassi et al., 2016 [22] & 13 & 23 & $100 \%$ & $82.6 \%$ & 1 year \\
\hline Perret et al., 2019 [26] & 6 & 6 & $100 \%$ & $100 \%$ & 2 years \\
\hline Engelke et al., 2014 [28] & 2 & 3 & $100 \%$ & - & 2 years \\
\hline Molly et al., 2006 [24] & 9 & 46 & $82.6 \%$ & - & $6-9$ years \\
\hline Beltrán et al., 2013 [30] & 1 & 1 & $100 \%$ & - & - \\
\hline Total & 39 & 88 & $96.5 \%$ & $91.3 \%$ & $1-9$ years \\
\hline
\end{tabular}

\section{Discussion}

According to the results obtained in the present systematic review, the horizontal bone gain was between 2.3 and $9 \mathrm{~mm}[22,25,26,29,30]$, and the vertical between 4.5 and $7.3 \mathrm{~mm}$ [22,26,31]. These last values without taking into account the randomized clinical trial in which alveolar ridge preservation of well-conserved post-extraction sockets was performed, in which the mean vertical gain was greater than $8 \mathrm{~mm}$ [38]. 
In a recent RCT comparing vertical bone gain by using d-PTFE titanium-reinforced membranes or titanium meshes, a gain of $4.2 \pm 1.0 \mathrm{~mm}$ (range 2.7-5.8) and $4.1 \pm 1.0 \mathrm{~mm}$ (range 2.6-6.3) was obtained, respectively [40]. Likewise, a meta-analysis obtained similar results, with a mean vertical bone gain of $4.42 \mathrm{~mm}$ by using non-resorbable membranes (d-PTFE and e-PTFE), of $4.26 \mathrm{~mm}$ by using titanium meshes covered by resorbable membranes and of $5.2 \mathrm{~mm}$ by using titanium meshes alone [41].

Based on these data, it appears that the use of titanium foils is predictable in terms of the amount of bone gain, regardless of the filling material, and the gain may be even higher than with the use of other commonly used non-resorbable membranes or meshes.

With regard to horizontal bone gain, the values obtained in the different studies analyzed are very heterogeneous and do not seem to be related to the filling material used either. Other studies in which horizontal regeneration procedures were performed with collagen membranes and particulate grafts obtained average bone gains of $2.27 \pm 1.68 \mathrm{~mm}$ [42], $5.68 \pm 1.42 \mathrm{~mm} \mathrm{[43]} \mathrm{and} 5.03 \pm 2.15 \mathrm{~mm}$ [44] Thus, it seems that, in terms of horizontal bone gain, titanium barriers are comparable to collagen membranes, the most widely used in horizontal ridge augmentation procedures.

Based on the included articles, there is no evidence to believe that a filling material is better than another or even blood clot, in combination with occlusive titanium barriers. Furthermore, this type of membrane could be useful in the regeneration of defects of different types, from contained defects such as a post-extraction socket to a combined vertical and horizontal defect such as a posterior mandibular atrophy.

Regarding complications, it appears that titanium foils are prone to exposure, as is the case of titanium meshes and non-resorbable membranes with titanium reinforcement. The mean exposure rate in the present work was $23.81 \%$ (range 0-50\%) [19,22,24,27-31,37-39], and the mean infection rate was $1.19 \%$ (range $0-11.9 \%$ ) $[19,22,25,26,28-31,37,38]$. If these results are compared with those of other studies, it can be observed that the rate of postoperative complications of titanium foils is slightly higher than that of GBR procedures with other types of membranes. In an RCT in which the rate of complications in vertical ridge augmentation was evaluated through the use of titanium meshes covered with collagen membranes and the use of non-resorbable membranes with titanium reinforcement, a postoperative complication rate (exposure and infection) of $21.1 \%$ and $15 \%$ was obtained, respectively [40]. A meta-analysis obtained an intra- and postoperative complications rate of $21 \%$ for titanium meshes covered with resorbable membranes, of $6.9 \%$ for non-resorbable membranes and of $20 \%$ for titanium meshes [41].

In different studies on the use of native collagen membranes in horizontal bone regeneration, a percentage of complications of 3.2\% [43] and $0 \%$ [44] was recorded. In a recent meta-analysis, an exposure rate of $28.62 \%$ for crosslinked membranes and of 20.74 for non-crosslinked membranes was obtained [42].

The postoperative complication rate of titanium barriers was higher than that of native collagen membranes and non-resorbable titanium-reinforced membranes, and similar to that of crosslinked collagen membranes and titanium meshes.

It must be taken into account that the complication rate obtained in this systematic review is surely lower than the real one in the included studies, since, in some articles, patients were excluded due to membrane displacement [37] or very premature exposure [27], not taking into account these cases in the complication rate reported. Furthermore, in two of the studies, some exposed membranes are associated with graft failure, but it is not specified whether it is due to graft infection [24,39].

On the one hand, some of the included articles defend that the exposure of the titanium foil does not influence the success of the GBR $[19,22,37,38]$, even if one of them sustains that the very early exposure favors the increase in width of the attached gingiva, unlike what happens with a later exposure [22]. On the other hand, two studies support that early exposure (before 14 days) has a worse prognosis than late exposure, with very poor bone gain [24,39].

From the results obtained, it appears that the survival rate of implants placed in regenerated bone is similar to that of implants placed in native bone [45]. 
This review is based on the scant scientific literature published on the matter so far, and, for the moment, it is the only existing systematic review, so the results obtained cannot be compared and cannot be given much value. Other limitations are the heterogeneity of the included studies, the small sample size of some of them and the lack of information regarding bone gain or membrane removal. For these reasons, a quantitative analysis could not be performed.

\section{Conclusions}

Based on the data presented above, titanium membranes in GBR should be considered as an incipient technique, versatile in terms of the type of bone defect to regenerate, in which there is still no evidence of the need of filling material and which is the most appropriate, that can better tolerate exposure than titanium meshes and titanium-reinforced non-resorbable membranes and that can be tailored to the patient's bone defect.

More randomized clinical trials comparing occlusive titanium barriers and other types of membranes are necessary to obtain more robust data that allow us to reach solid conclusions regarding the predictability and complications rate associated with the use of titanium foils, and how to manage complications when they occur.

Author Contributions: Conceptualization, E.R.-M. and A.E.-D.; methodology, E.R.-M. and A.E.-D.; validation, E.R.-M., E.J.-S. and J.L.-L.; formal analysis, E.R.-M. and A.E.-D.; investigation, E.R.-M. and A.E.-D.; resources, J.L.-L.; data Curation, E.R.-M. and J.L.-L.; writing-original draft preparation, E.R.-M. and A.E.-D.; writing-review and editing, E.J.-S. and J.L.-L.; visualization, E.R.-M. and J.L.-L.; supervision, E.J.-S. and J.L.-L.; project administration, A.E.-D. and J.L.-L. All authors have read and agreed to the published version of the manuscript.

Funding: This research received no external funding.

Conflicts of Interest: The authors declare no conflict of interest.

\section{References}

1. Wang, H.-L.; Boyapati, L. “PASS” principles for predictable bone regeneration. Implant Dent. 2006, 15, 8-17. [CrossRef] [PubMed]

2. McAllister, B.S.; Hahgighat, K. Bone augmentation techniques. J. Periodontol. 2007, 78, 277-296. [CrossRef] [PubMed]

3. Benic, G.I.; Hämmerle, C.H.F. Horizontal bone augmentation by means of guided bone regeneration. Periodontology 2000 2014, 66, 13-40. [CrossRef]

4. Bertolino, V.; Cavallaro, G.; Milioto, S.; Lazzara, G. Polysaccharides/Halloysite nanotubes for smart bionanocomposite materials. Carbohydr. Polym. 2020, 245, 116502. [CrossRef] [PubMed]

5. Cavallaro, C.; Lazzara, G.; Fakhrullin, R. Mesoporous inorganic nanoscale particles for drug adsorption and controlled release. Ther. Deliv. 2018, 9, 287-301. [CrossRef]

6. Soldatos, N.K.; Stylianou, P.; Koidou, V.P.; Angelov, N.; Yukna, R.; Romanos, G.E. Limitations and options using resorbable versus nonresorbable membranes for successful guided bone regeneration. Quintessence Int. 2017, 48, 131-147.

7. Cardaropoli, G.; Araújo, M.; Lindhe, J. Dynamics of bone tissue formation in tooth extraction sites. An experimental study in dogs. J. Clin. Periodontol. 2003, 30, 809-819. [CrossRef]

8. Araújo, M.G.; Lindhe, J. Dimensional ridge alterations following tooth extraction. An experimental study in dog. J. Clin. Periodontol. 2005, 32, 212-218. [CrossRef]

9. Srinivas, B.; Das, P.; Rana, M.M.; Qureshi, A.Q.; Vaidya, K.C.; Raziuddin, S.J.A. Wound healing and bone regeneration in postextraction sockets with and without platelet-rich fibrin. Ann. Maxillofac. Surg. 2018, 8 , $28-34$.

10. Li, J.; Chen, M.; Wei, X.; Hao, Y.; Wang, J. Evaluation of 3D-printed polycaprolactone scaffolds coated with freeze-dried platelet-rich plasma for bone regeneration. Materials 2017, 10, 831. [CrossRef]

11. Batas, L.; Tsalikis, L.; Stavropoulos, A. PRGF as adjunct to DBB in maxillary sinus floor augmentation: Histological results of a pilot Split-mouth study. Int. J. Implant Dent. 2019, 5, 14. [CrossRef] [PubMed]

12. Gersh, K.C.; Nagaswami, C.; Weisel, J.W. Fibrin network structure and clot mechanical properties are altered by incorporation of erythrocytes. Thromb. Haemost. 2009, 102, 1169-1175. [CrossRef] [PubMed] 
13. Thor, A.; Rasmusson, L.; Wennerberg, A.; Thomsen, P.; Hirsch, J.-M.; Nilsson, B.; Hong, J. The role of whole blood in thrombin generation in contact with various titanium surfaces. Biomaterials 2007, 28, 966-974. [CrossRef] [PubMed]

14. Polimeni, G.; Koo, K.-T.; Qahash, M.; Xiropaidis, A.V.; Albandar, J.M.; Wikesjö, M.E. Prognostic factors for alveolar regeneration: Effect of a space-providing biomaterial on guided tissue regeneration. J. Clin. Periodontol. 2004, 31, 725-729. [CrossRef]

15. Jovanovic, S.S.; Nevins, M. Bone formation utilizing titanium-reinforced barrier membranes. Int. J. Periodontics Restor. Dent. 1995, 15, 56-69. [CrossRef]

16. Simion, M.; Trisi, P.; Piattelli, A. Vertical risge augmentation using a membrane technique associated with osseointegrated implants. Int. J. Periodontics Restor. Dent. 1994, 14, 496-511.

17. Elgali, I.; Omar, O.; Dahlin, C.; Thomsen, P. Guided bone regeneration: Materials and biological mechanisms revisited. Eur. J. Oral Sci. 2017, 125, 315-337. [CrossRef]

18. Caballé-Serrano, J.; Munar-Frau, A.; Ortiz-Puigpelat, O.; Soto-Penaloza, D.; Peñarrocha, M.; Herández-Alfaro, F. On the search of the ideal barrier membrane for guided bone regeneration. J. Clin. Exp. Dent. 2018, 10, e477-e483. [CrossRef]

19. Kfir, E.; Kfir, V.; Kaluski, E. Immediate bone augmentation after infected tooth extraction using titanium membranes. J. Oral Implantol. 2007, 33, 133-138. [CrossRef]

20. Bassi, M.A.; Andrisani, C.; Lico, S.; Ormanier, Z.; Ottria, L.; Gargari, M. Guided bone regeneration via a performed titanium foil: Clinical, histological and histomorphometric outcome of a case series. Oral Implantol. 2016, 9, 164-174.

21. Van Steenberghe, D.; Johansson, C.; Quirynen, M.; Molly, L.; Albrektsson, T.; Naert, I. Bone augmentation by means of a stiff occlusive titanium barrier. Clin. Oral Implants Res. 2003, 14, 63-71. [CrossRef] [PubMed]

22. Bassi, M.A.; Andrisani, C.; López, M.A.; Gaudio, R.M.; Lombardo, L.; Lauritano, D. Guided bone regeneration in distal mandibular atrophy by means of a performed titanium foil: A case series. J. Biol. Regul. Homeost. Agents 2016, 30, 61-68.

23. Bassi, M.A.; Andrisani, C.; López, M.A.; Gaudio, R.M.; Lombardo, L.; Carinci, F. Guided bone regeneration by means of a preformed titanium foil: A case of severe atrophy of edentulous posterior mandible. J. Biol. Homeost. Agents 2016, 30, 35-41.

24. Molly, L.; Quirynen, M.; Michiels, K.; van Steenberghe, D. Comparison between jaw bone augmentation by means of a stiff occlusive titanium membrane or an autologous hip graft: A retrospective clinical assessment. Clin. Oral Implants Res. 2006, 17, 481-487. [CrossRef]

25. Mauricio, E.J.M.; Faveri, M.; de Silva, H.D.P. Alveolar ridge regeneration of damaged extraction sockets using bovine-derived bone graft in association with a titanium foil: Prospective case series. J. Int. Acad. Periodontol. 2020, 22, 109-116.

26. Perret, F.; Romano, F.; Ferrarotti, F.; Aimetti, M. Occlusive titanium barrier for immediate bone augmentation of severely resorbed alveolar sockets with secondary soft tissue healing: A 2-year case series. Int. J. Periodontics Restor. Dent. 2019, 39, 97-105. [CrossRef]

27. Toygar, H.U.; Guzeldemir, E.; Cilasun, U.; Akkor, D.; Arpak, N. Long-term clinical evaluation and SEM analysis of the e-PTFE and titanium membranes in guided tissue regeneration. J. Biomed. Mater. Res. $B$ Appl. Biomater. 2009, 91, 772-779. [CrossRef]

28. Engelke, W.; Deccó, O.; Cura, A.C.; Borie, E.; Beltrán, V. Rigid occlusive titanium barriers for alveolar bone augmentation: Two reports with 24-month follow-up. Int. J. Clin. Exp. Med. 2014, 7, 1160-1165.

29. Beltrán, V.; Engelke, W.; Fuentes, R.; Decco, O.; Prieto, R.; Wilckens, M.; Borie, E.; Beltran, V.; Engelke, W.; Fuentes, R.; et al. Bone augmentation with occlusive barriers and cortical particulate allograft in transverse maxillary defects: A pilot study. Int. J. Morphol. 2014, 32, 364-368. [CrossRef]

30. Beltrán, V.; Matthijs, A.; Borie, E.; Fuentes, R.; Valdivia-Gandur, I.; Engelke, W. Bone healing in transverse maxillary defects with different surgical procedures using anorganic bovine bone in humans. Int. J. Morphol. 2013, 31, 75-81. [CrossRef]

31. Gaggl, A.; Schultes, G. Titanium foil-guided tissue regeneration in the treatment of periimplant bone defects. Implant Dent. 1999, 8, 368-375. [CrossRef] [PubMed]

32. Moher, D.; Liberati, A.; Tetzlaff, J.; Altman, D.G. PRISMA Group. Preferred reporting ítems for systematic reviews and meta-analyses: The PRISMA statement. PLoS Med. 2009, 6, e1000097. [CrossRef] [PubMed] 
33. Ebell, M.H.; Siwek, J.; Weiss, B.D.; Woolf, S.H.; Susman, J.; Ewigman, B.; Bowman, M. Strenght of recommendation taxonomy (SORT): A patient-centered approach to grading evidence in the medical literatura. Am. Fam. Phys. 2004, 69, 548-556.

34. Sterne, J.A.C.; Savović, J.; Page, M.J.; Elbers, R.G.; Blencowe, N.S.; Boutron, I. RoB 2: A revised tool for assessing risk of bias in randomised trials. BMJ 2019, 366, 14898. [CrossRef] [PubMed]

35. Sterne, J.A.; Hernán, M.A.; Reeves, B.C.; Savović, J.; Berkman, N.D.; Viswanathan, M. ROBINS-1: A tool for assessing risk of bias in non-randomised studies of interventions. BMJ 2016, 355, i4919. [CrossRef] [PubMed]

36. Vrielinck, L.; Sun, Y.; Schepers, S.; Politis, C.; Slycke, S.V.; Agbaje, J.O. Osseous reconstruction using an occlusive titanium membrane following marginal mandibulectomy: Proof of principle. J. Craniofac. Surg. 2014, 25, 1112-1114. [CrossRef] [PubMed]

37. Khanna, R.; Khanna, R.; Pardhe, N.D.; Srivastava, N.; Bajpai, M.; Gupta, S. Pute titanium membrane (Ultra-Ti ${ }^{\circledR}$ ) in the treatment of periodontal osseous defects: A split-mouth comparative study. J. Clin. Diagn. Res. 2016, 10, ZC47-ZC51.

38. Pinho, M.N.; Roriz, V.L.M.; Novaes, A.-B.; Taba, M.; Grisi, M.F.M.; de Souza, S.L.S.; Palioto, D.B. Titanium membranes in prevention of alveolar collapse after tooth extraction. Implant Dent. 2006, 15, 53-61. [CrossRef]

39. Watzinger, F.; Luksch, J.; Millesi, W.; Schopper, C.; Neugebauer, J.; Moser, D.; Ewers, R. Guided bone regeneration with titanium membranes: A clinical study. Br. J. Oral Maxillofac. Surg. 2000, 38, 312-315. [CrossRef]

40. Cucchi, A.; Vignudelli, E.; Napolitano, A.; Marchetti, C.; Corinaldesi, G. Evaluation of complication rates and vertical bone gain after guided bone regeneration with non-resorbable membranes versus titanium meses and resorbable membranes. A randomized clinical trial. Clin. Implant Dent. Relat. Res. 2017, 19, 821-832. [CrossRef]

41. Urban, I.A.; Montero, E.; Monje, A.; Sanz-Sánchez, I. Effectiveness of vertical ridge augmentation interventions: A systematic review and meta-analysis. J. Clin. Periodontol. 2019, 46, 319-339. [CrossRef] [PubMed]

42. Wessing, B.; Lettner, S.; Zechner, W. Guided bone regeneration with collagen membranes and particulate graft materials: A systematic review and meta-analysis. Int. J. Oral Maxillodac. Implants 2018, 33, 87-100. [CrossRef] [PubMed]

43. Urban, I.A.; Nagursky, H.; Lozada, J.L.; Nagy, K. Horizontal risge augmentation with a collagen membrane and a combination of particulated autogenous bone and anorganic bovine bone-derived mineral: A prospective case series in 25 patients. Int. J. Periodontics Restor. Dent. 2013, 33, 299-307. [CrossRef] [PubMed]

44. Meloni, S.M.; Jovanovic, S.A.; Urban, I.; Baldoni, E.; Pisano, M.; Tallarico, M. Horizontal ridge augmentation using GBR with a native collagen membrane and 1:1 ratio of particulate xenograft and autologous bone: A 3-year after final loading prospective clinical study. Clin. Implant Dent. Relat. Res. 2019, 21, 669-677. [CrossRef]

45. Moraschini, V.; Poubel, L.A.; Ferreira, V.F.C.; Barboza, E.S.P. Evaluation of survival and success rates of dental implants reported in longitudinal studies with a follow-up period of at least 10 years: A systematic review. Int. J. Oral Maxillofac. Surg. 2015, 44, 377-388. [CrossRef]

Publisher's Note: MDPI stays neutral with regard to jurisdictional claims in published maps and institutional affiliations.

(C) 2020 by the authors. Licensee MDPI, Basel, Switzerland. This article is an open access article distributed under the terms and conditions of the Creative Commons Attribution (CC BY) license (http://creativecommons.org/licenses/by/4.0/). 